\title{
Temperature Sensor Device
}

National Cancer Institute

\section{Source}

National Cancer Institute. Temperature Sensor Device. NCI Thesaurus. Code C50304.

A sensor designed to respond to the temperature of a space, surface, or environment. 